\begin{tabular}{|c|c|}
\hline & $\begin{array}{l}\text { Journal of Communication Pedagogy } \\
\qquad 2019, \text { Vol. 2, 127-133 }\end{array}$ \\
\hline $\begin{array}{l}\text { COMMUNICATION } \\
\text { PEDAGOGY }\end{array}$ & $\begin{array}{r}\text { OThe Author(s) } 2019 \\
\text { Reprints and permissions: http://www.csca-net.oro }\end{array}$ \\
\hline & $\begin{array}{r}\text { DOI: } 10.31446 / J C P .2019 .22 \\
\text { Central States Communication Association }\end{array}$ \\
\hline
\end{tabular}

\title{
Developing a Digital Voice: Embedding Digital Communication Networks, Platforms, and Technologies in the 21 st-Century Classroom
}

\author{
James M. Proszek
}

Keywords: digital media, technology, communication pedagogy, introductory course

\begin{abstract}
Introductory communication courses are an invaluable resource for improving students' abilities to speak confidently, passionately, and persuasively, while also inspiring them to become more engaged citizens. However, digital media present new opportunities and challenges for designing courses that are relevant to students' personal and professional interests and goals. Instructors who incorporate digital communication platforms, networks, and technologies into their classrooms can better prepare students to meet the complex demands of the technologically-mediated 21 st century. In this essay, I offer 10 best practices for developing students' digital media literacies within multiple communication contexts.
\end{abstract}

Increasingly sophisticated electronic communication networks, platforms, and technologies have opened new avenues and raised significant challenges to teaching in the 21 st-century classroom. Educators have responded well to the demands, challenges, and possibilities of creating digitally mediated classrooms and engaging their tech-savvy students through sustained research in the connections between "Web 2.0" and pedagogy (Greenhow, Robelia, \& Hughes, 2009; Hew \& Cheung, 2013). Communication pedagogy scholars have recognized the importance of incorporating digital technologies into communication studies, particularly within introductory-level survey and hybrid courses with public speaking components (Frisby, 2017; Kirkwood, Gutgold, \& Manley, 2011; Lind, 2012; Morreale, Myers, Backlund, \& Simonds, 2016; Oh \& Owlett, 2017). This essay offers 10 best practices for teaching students to develop their "digital voices" by embedding digital networks, platforms, and technologies into a variety of communication topics and courses. 


\section{Best Practice \#1: Promote Media Literacy}

Introductory-level communication studies survey and hybrid courses often attract students from varying cultural and disciplinary backgrounds who have diverse experiences, competencies, and anxieties in addressing an audience, and who bring different expectations for how the course will foster long-term success in their professional and private lives. Creating a common ground for the classroom experience is thus one of the most vital and yet one of the most challenging aspects of course design. Promoting media literacy can serve as a foundation and framework for preparing students to participate in digitally mediated environments in and beyond the classroom. According to the National Association for Media Literacy Education, media literacy is the ability to assess, analyze, evaluate, create, and act using all forms of communication, which are vital skills given the overwhelming amount of information and screens demanding one's constant attention. To teach students how to assess, analyze, and evaluate messages across different media, I design listening and viewing assignments to pair with each unit and chapter from the course textbook. Commercial print and television ads, for example, are great tools for teaching Aristotle's means of persuasion, because students can actively describe how the images or dialogue in each advertisement functions as an appeal to reason, emotion, authority, or some combination of each. However, it also is important for students to take an active role in sharing video, audio, and text materials with one another to bring the course concepts to life. Each week in my class, for example, two students serve as "digital curators." They submit a video, audio clip, or article to the course website and write a paragraph-long description about how the piece relates to the week's readings. Another way in which I promote literacy is when students draft their speeches in the course, I ask them to devise a strategy for how they would develop this speech to reach an audience outside of the classroom, paying particular attention to the digital technologies available to them. This reflective process encourages students to think of themselves not only as consumers, but also as producers of mediated content.

\section{Best Practice \#2: Incorporate Digital Technologies Into In-Class Discussions and Activities}

Digital technologies are revolutionizing communication education, not only by offering plentiful new resources and tools for teaching and learning, but also by transforming the structure of the classroom itself (Morreale et al., 2016). E-textbooks, learning management systems, and mobile applications are now commonplace even in more traditional formats of survey and hybrid communication studies courses. Instructors should develop a technology policy in the course syllabus for using digital platforms and devices strategically during in-class discussions and activities. Instructors must convey to students that digital platforms and devices are not potential distractions to be removed from the classroom, but rather educational resources. During in-class discussions, I have students identify major and/ or common questions and observations about readings and assignments using their laptops, tablets, or phones to access the course's online discussion board. This encourages students to visualize digital and face-to-face discussion practices as productively connected. For in-class activities, I incorporate "context statements," which are questions or tasks requiring students to connect to the Internet. For example, when I teach argumentation structure, I ask students to find online articles and write a context statement in which they identify the claims, warrants, and evidence in the articles. While digital platforms and technologies provide many opportunities to enhance student learning, instructors may face several hurdles incorporating them into discussions and activities. Digital technologies may not be uniformly implemented across institutions; instructors may, therefore, have to invest time and resources to learn how to use and teach with new software platforms. Technology policies should identify specific digital 
resources available to instructors and students and how those resources will be used in in-class discussion and activities.

\section{Best Practice \#3: Reimagine Public Address}

As with earlier forms of media (e.g., newsprint, radio, television), the advent of digital media signals exciting new possibilities for the study of public address. In fact, Kennerly and Pfister (2018) observed that "despite early concerns that the advent of digital mediation portended further marginalization of public address, digital media technologies appear at least partially responsible for an oratory boom" (p. 4). Digital platforms and technologies are an invaluable resource for teaching American public address. Special projects such as Voices of Democracy provide essays, analyses, and curriculum units on many historic U.S. speeches and debates. TED Talks, YouTube videos, Facebook and Twitch live streams, and Instagram stories represent a growing body of digital platforms that instructors can use to teach students how to analyze contemporary forms of public address. TED Talks, which deliver over 3,000 engaging, easy-to-access lectures on a wide variety of subjects, are perfect models for students to study the mechanics of verbal and nonverbal delivery and how to structure a speech's content. Before the first major speech assignment, I have each student identify a topic of personal interest and then select two different TED Talks on that topic. Students then write a comparative analysis paper on the similarities and differences between each speaker's verbal dynamics and body language and evaluate how verbal and nonverbal delivery adds to or detracts from their overall performance, and identify the types of arguments and evidence the speakers use to build the content of their address, their tone and engagement with the audience, and their use of visual aids, if applicable. I then ask students to identify elements of each speech that they would or would not incorporate into their own presentations and why those elements stood out to them. Students are thus able to study contemporary examples of public address through digital platforms to develop their own oratorical competencies.

\section{Best Practice \#4: Build Electronic Portfolios}

Introductory communication courses with public speaking components are well-suited for developing student electronic portfolios where students can showcase their speech activities and performances. Case studies conducted by JISC (2008), a UK-based digital education and research group, have shown that building e-portfolios serves multiple purposes, including (1) improving self-understanding and understanding of the curriculum, (2) engaging and motivating learners, (3) personalizing learning, (4) supporting models of learning appropriate to a digital age, and (5) promoting reflective practice. Creating a digital copy of their speeches empowers students to think about the value of their work beyond the classroom space and encourages them to visualize their growth as speakers throughout the course. I encourage instructors to use third-party platforms to store files and build portfolios over their institution's learning management systems (Canvas, Blackboard) to ensure students will not lose their work after the end of the course, graduating, or changing institutions. Instructors who are new to creating digital portfolios or are uncomfortable with using sophisticated e-portfolio platforms and design tools can create very basic e-portfolios using Google Drive, Dropbox, or Google Sites. No matter how simple or complex, building e-portfolios should be a collaborative effort. Students can add completed assignments, presentations, artifacts relevant to their projects (e.g., newspaper and journal articles and reflections), whereas instructors can provide detailed feedback for students' written work and oral presentations and their overall progress in the course. 


\section{Best Practice \#5: Incorporate Video Platforms}

In today's digitally-mediated, screen-saturated environments, screen-to-screen communication is quickly becoming a dominant mode of both private and public address (Frisby, 2017; Kirkwood et al., 2011). Individuals are using video software to keep in touch with geographically distant friends (e.g., FaceTime, WhatsApp, and Hangouts) and to broadcast themselves to larger audiences (e.g., YouTube, Facebook Live, Instagram stories). Companies are utilizing different recording and streaming services to conduct interviews and internal meetings (Skype, Slack) and to create and share content with clients. Instructors, therefore, must prepare students to communicate effectively using video recording and broadcast technologies to meet the demands of a digitally-connected world (Lind, 2012). One way to do so is to transform a major speech assignment into a mock interview session. After students have delivered an informative or persuasive speech, instructors can ask students to distribute their working outline to several classmates, who then will prepare a series of questions as if the speaker and the speech were being profiled for a newspaper or magazine article. Instructors then can use the Skype video platform to facilitate the interview. Speakers must rely on the content of their speech and their sources to provide extemporaneous answers to their peers' interview questions; instructors should note how the speakers answer questions and how they manage their body language through the webcam. When conducting this assignment, instructors should consider potential barriers students may face when accessing and using digital resources such as finding a private space to communicate, maintaining stable Internet connection, and purchasing the latest software and hardware (Hawkins \& Oblinger, 2006). Once the mock interview is completed, instructors can use Skype to provide feedback about the student's performance. When giving feedback, instructors should focus on developing students' proficiencies and reducing their anxieties in addressing an audience through video platforms, just as they would with a face-to-face audience.

\section{Best Practice \#6: Assess the Dynamics of Digital Audiences}

Many incoming students are seasoned Internet users with considerable experience interacting with and acting as digital audiences. However, audience analysis concepts and techniques taught in communication textbooks, sample speeches, and assignments are predominantly geared toward material audiences that occupy a physical space. Instructors, therefore, must make a conscious effort to demonstrate how audiences access, convene, listen, and respond through digitally mediated networks and technologies. One activity that encourages students to critically think about and engage with the dynamics of digital audiences is to develop a series of imaginative hypothetical scenarios such as an end-of-the-world event or the discovery of a cure for cancer, and then challenge students to summarize and respond to the scenarios using the dominant mediums of different historical periods. Students form small groups and select a hypothetical scenario and an audience that primarily receives news from (1) a newspaper, (2) a radio broadcast, (3) a televised breaking news report, or (4) a Tweet or other type of social media post. Each group constructs a message addressing the hypothetical scenario, explains how the message fits the structural features of the particular medium, and describes how the audience would access and respond to the message. After each group presents their scenario and message, the entire class then identifies differences in each group's message and discusses how the context of the scenario and the medium affect the structure and content of the messages. Major current events such as a recent presidential address or upcoming global summit can be used in place of hypothetical scenarios by instructing students to find an actual message from a contemporary medium and have them describe how the content and delivery of the message would change if it were delivered in an earlier historical period. 


\section{Best Practice \#7: Create Course-Specific Social Media Accounts}

Social media plays a vital role in shaping complex digital communities. However, individual usersmany of whom are students-tend to frame their participation in these communities as a private affair. Thus, while educators have spent over a decade studying and incorporating different social networking sites in the classroom (Gupta, 2014), encouraging students to embrace social media as an educational resource remains a tremendous challenge. For communication pedagogy scholars and teachers, it is a challenge worth taking. Within the context of the basic communication course, Oh and Owlett (2017) described how incorporating social media transforms assignments and activities "to better suit the current media diets of students" and fosters multiple long-term learning outcomes such as strengthening students' "sense of political and civic engagement" (pp. 100-102). Creating course-specific social media accounts can foster dynamic, robust opportunities for students to use social networking sites in the classroom. For example, I create Facebook, Twitter, YouTube, and Instagram pages for each course I am teaching. On the first day of class, I introduce the students to these pages and put the account handles on the syllabus. Each account is purposely generic in the beginning and devoid of all but the most basic information, but is then developed collaboratively throughout the course using concepts from the textbooks and discussions. In addition to uploading relevant external examples and resources to these accounts every few weeks, instructors can use them as a platform for discussions about the dynamics of communicating through social networking sites and the importance of social media literacy. These discussions include topics such as what is considered to be "public" and "private" information on social media platforms, how to critically evaluate different types of posts, and what constitutes "participation" in digital communities.

\section{Best Practice \#8: Discuss Digital Identities}

Discussions about social media are not limited to the platforms themselves, they also address "digital identities," or the complex ways in which individuals conceal and disclose information about who they are in digital spaces. Users must now make conscious choices about how much information they share about themselves - a decision often constrained by what information websites and applications require individuals to provide to gain access to content (e.g., name, e-mail, mobile number). Furthermore, digital environments present a unique set of affordances and limitations to establishing credibility with an audience. To demonstrate this, I divide students into small groups and assign each group a social media site such as Facebook, Tumblr, Reddit, and so forth. I encourage students to consider how digital identities often are mediated by the norms, practices, and features of specific websites. Using the assigned platform, each group explores how both a celebrity and an average individual would establish their expertise or experience on a topic. For example, students can compare how a celebrity and an amateur chef use social media to demonstrate their culinary knowledge and skills. In a post-assignment discussion, I focus on how the students connect the practices and concepts they identify in small group discussions with their own individual digital practices and identities.

\section{Best Practice \#9: Analyze Misleading Articles and Sources}

Digital technologies have sparked an information revolution that not only is changing how information is accessed, but also how the information itself is created and distributed. The latter has raised serious concerns about source credibility and the purposeful spread of misinformation through electronic communication networks, which demands that educators teach students the proper information literacy skills to distinguish between reliable and biased or misleading sources and to conduct responsible 
research practices (Meyer et al., 2008). A 2016 study conducted by the Stanford History Education Group found that across middle, high school, and college levels of learning, students' "ability to reason about the information on the internet can be summed up in one word: bleak" (p. 4). Instructors must teach students how to track and analyze articles with misleading information and/or biased sources. One way I do so is by giving students a list of fake news websites (e.g., CBS, Wikipedia, and FactCheck.org), having them select an article from one of the sites, marking any information that seems suspect, and comparing the information with other news organizations for corroboration. Through a short essay or oral presentation, students explain how much of the article is false, what red flags appeared in its content, and (if possible) how the article circulated on the Internet. During the activity debriefing, instructors should encourage students to adopt and share positive, responsible fact-checking and citation practices. Students can read, discuss, and take the Pro-Truth Pledge as a first step to promoting proactive research strategies.

\section{Best Practice \#10: Build Library Partnerships}

The massive amount of digital information and the complexity of Internet search tools and platforms pose a serious challenge to students as they strive to find reliable evidence from credible sources for their speeches. However, building partnerships with campus and community libraries can teach students how to navigate the world of information and develop responsible practices for conducting academic research (Carpan, 2011; Gaspar \& Wetzel, 2009). Library partnerships are important not only for developing speeches during the course, but also serve students' long-term educational goals by enabling them to continue to conduct quality research after the class is over. Instructors can take the first step by contacting librarians-colleges and universities often have subject-specific librarians who are familiar with the disciplinary nuances of conducting research-to assess what resources are available to students. However, it also is important to establish connections with local public libraries-many of which have their own robust digital collections-because students will not have permanent access to university library resources. Library partnerships create opportunities for collaborative teaching, in that instructors can invite library staff members into their classrooms to provide an overview of library resources and services and demonstrate how students can use them, or set aside class time to visit a campus or public library. One activity that is popular with my students when preparing for formal speech presentations is to make a "mind map" where they write all key words and search terms associated with their speech topic. They then strategically pair these terms in different combinations using newly acquired database search techniques to create a list of possible sources for their speeches. Often, this use generates new ideas and information that they otherwise would not have considered.

\section{Conclusion}

Of the many challenges that digital networks, platforms, and technologies present to instructors as discussed in the aforementioned Best Practices, the greatest challenge is in the nature of the medium itself-electronic programs and devices are continuously updating and adding new capabilities, user bases on social networking sites are constantly growing, and online communication norms and practices are becoming more complex. As communication instructors and scholars, the ideas and strategies used to assist students to develop their digital voices must also follow an adaptive, innovative path. Thus, I present these 10 Best Practices not as a definitive set for how to incorporate digital oratory comprehensively into multiple communication studies courses and special topics, but as the opening of a conversation and the start of a movement to be further shaped and shared by the dedicated members of this community. 


\section{References}

Carpan, C. (2011). The importance of library liaison programs. College \& Undergraduate Libraries, 18, 104-110. doi:10.1080/10691316.2011.550536

Frisby, B. N. (2017). Capitalizing on the inevitable: Adapting mobile technology to the basic communication course. Basic Communication Course Annual, 29, 75-82. Retrieved from https://ecommons. udayton.edu/bcca/vol29/iss1/8

Gaspar, D., \& Wetzel, K. (2009). A case study in collaboration: Assessing academic librarian/faculty partnerships. College \& Research Libraries, 70, 578-591. doi:10.5860/0700578

Greenhow, C., Robelia, B., \& Hughes, J. (2009). Learning, teaching, and scholarship in a digital age: Web 2.0 and classroom research: What path should we take now? Educational Researcher, 38, 246-259. doi:10.3102/0013189X09336671

Gupta, A. (2014). Scope and implications of social media in the context of higher education: Review of researches. MIER Journal of Educational Studies, Trends and Practices, 4, 231-253.

Hawkins, B. L., \& Oblinger, D. G. (2006). The myth about the digital divide: 'We have to overcome the digital divide.' EDUCAUSE REVIEW, 41(4), 12-13. Retrieved from https://er.educause.edu/ articles/2006/1/the-myth-about-the-digital-divide

Hew, K. F., \& Cheung, W. S. (2013). Use of Web 2.0 technologies in K-12 and higher education: The search for evidence-based practice. Educational Research Review, 9, 47-64. doi:10.1016/j.edurev.2012.08.001

JISC. (2008). Effective practice with e-portfolios: Supporting 21st century learning [PDF file]. Retrieved from http://www.jisc.ac.uk/media/documents/publications/effectivepracticeeportfolios.pdf

Kennerly, M., \& Pfister, D. S. (2018). Introduction. In M. Kennerly \& D. S. Pfister (Eds.), Ancient rhetorics \& digital networks (pp. 1-27). Tuscaloosa, AL: The University of Alabama Press.

Kirkwood, J., Gutgold, N. D., \& Manley, D. (2011). Hello world, it's me: Bringing the basic speech communication course into the digital age. Communication Teacher, 25, 150-153. doi:10.1080/17404622. 2011.579905

Lind, S. J. (2012). Teaching digital oratory: Public speaking 2.0. Communication Teacher, 26, 163-169. doi:10.1080/17404622.2012.659193

Meyer, K. R., Hunt, S. K., Hopper, K. M., Thakkar, K. V., Tsobanopoulos, V., \& Van Hoose, K. J. (2008). Assessing information literacy instruction in the basic communication course. Communication Teacher, 22, 22-34. doi:10.1080/17404620801926925

Morreale, S. P., Myers, S. A., Backlund, P. M., \& Simonds, C. J. (2016). Study IX of the basic communication course at two- and four-year U.S. colleges and universities: A re-examination of our discipline's front porch. Communication Education, 65, 338-355. doi:10.1080/03634523.2015.1073339

Oh, S.-K., \& Owlett, J. S. (2017). Embracing social media in the basic communication course: Recommendations for the digital age. Basic Communication Course Annual, 29, 98-108. Retrieved from https://ecommons.udayton.edu/bcca/vol29/iss1/11

Stanford History Education Group. (2016, November 22). Evaluating information: The cornerstone of civic online reasoning. Executive Summary [PDF file]. Retrieved from https://stacks.stanford.edu/ file/druid:fv751yt5934/SHEG\%20Evaluating\%20Information\%20Online.pdf 